\title{
Sotaques do poder: recombinações visuais e os fundamentos do imaginário régio judaíta
}

\author{
Accents of power: visual recombination and the \\ foundations of the Judahite royal imaginary
}

\section{Acentos de poder: recombinaciones visuales y los fundamentos del imaginario real judío}

\author{
Silas Klein Cardoso* \\ Submetido em: 28-6-2021 \\ Aceito em: 23-8-2021
}

* Universität Zürich (Suíça); Universität Bern (Suíça)

Pós-doutorando em Estudos da Religião

E-mail: silasklein@gmail.com

\begin{abstract}
RESUMO
A partir da análise iconográfica dos selos de estampar da região do platô de Benjamin no Ferro I-IIB, o artigo examina a presença de conceitos de realeza. Reconhecida na literatura política no decorrer da história pelas personalidades "bíblicas" que abrigou, a região ainda não viu um estudo dedicado à ideologia real feito exclusivamente com fontes visuais primárias em recorte. $\mathrm{O}$ estudo cresce em importância uma vez que se note que, mesmo no contexto judaíta, a iconografia da região fronteiriça de Benjamin provavelmente serviu de elo entre o imaginário real de Israel e Judá. Argumenta-se que no Período do Ferro I-IIA, a iconografia realça aspectos de vigor e filiação divina dos reis, estes criados à sombra do domínio egípcio, enquanto, no Ferro IIA tardio-IIB, ela passa a enfatizar a agressividade e perfil vitorioso dos reis.

Palavras-chave: Realeza; Benjamin; antigo Israel e Judá; iconografia; Bíblia Hebraica/ Antigo Testamento.
\end{abstract}

\footnotetext{
ABSTRACT

Based on the iconographic analysis of stamp seals from the Benjamin Plateau region in Iron I-IIB, the paper examines the presence of kingship concepts. Recognized in political literature throughout history for the "biblical" personalities it housed, the region has not seen a dedicated study of royal ideology done exclusively with primary visual sources from the constrained area. The study grows in importance once it is noted that, even in the Judaic context, the iconography of the border region of Benjamin likely served as a link between the royal imagery of Israel and Judah. It is argued that in the Iron I-IIA period, the iconography emphasizes aspects of vigor and divine sonship of the kings, these created in the shadow of Egyptian rule, while in late Iron IIA-IIB, it shifts to emphasizing the kings' aggressiveness and victorious profile.

Keywords: Kingship; Benjamin; ancient Israel and Judah; iconography; Hebrew Bible/Old Testament.

\section{RESUMEN}

A partir de la interpretación iconográfica de sellos de la región de la Meseta de Benjamín en el Hierro I-IIB, el artículo examina de conceptos de realeza. Reconocida en la literatura política a lo largo de la historia por las personalidades "bíblicas" que albergó, la región aún
} 
no ha visto un estudio dedicado a la ideología real realizado exclusivamente con fuentes visuales primarias en recorte. El estudio adquiere mayor importancia una vez que se observa que, incluso en el contexto judaico, la iconografía de la región fronteriza de Benjamín probablemente sirvió de enlace entre la imaginería real de Israel y Judá. Se argumenta que en el periodo Hierro IIA, la iconografía enfatiza aspectos de vigor y filiación divina de los reyes, estos creados a la sombra del dominio egipcio, mientras que a finales del Hierro IIA-IIB, pasa a enfatizar la agresividad y el perfil victorioso de los reyes.

Palabras clave: Realeza; Benjamín; antiguo Israel y Judá; iconografía; Biblia hebrea/Antiguo Testamento.

\section{Introdução}

Por algum motivo que só podemos conjecturar - do qual a canonização judaico-cristã de suas histórias certamente exerce seu papel-, eventos da região montanhosa central de Canaã no Período do Ferro I-IIA antigo (c. sécs. 12-10 aEC) continuam a reverberar na literatura política três mil anos depois. Personagens do imaginário ocidental, Saul, Davi e Salomão figuraram no discurso de influentes pensadores e pensadoras políticas nos últimos séculos. Nicolau Maquiavel, Thomas Hobbes, Baruch Spinoza e Hanna Arendt, para citar alguns, têm em comum o fato de tomarem essas figuras "bíblicas" para argumentar contra ou a favor das estruturas de poder de seu tempo (KIPFER; HUTTON, 2021, p. 17-19; KIPFER, 2015, p. 317-19; além da literatura política, veja EHRLICH, 2016). Aqui não é importante definir o grau de historicidade das personagens, mas notar como narrativas do período foram capazes de ecoar por séculos, remodelando-se e traduzindo-se para novas culturas. Tratar, portanto, da "Realeza no Mundo Antigo Oriental", tema deste dossiê, não implica pensar apenas num passado longínquo e desconexo, mas em um que, de alguma maneira - e, com certeza, sob muitos vieses - ainda nos atinge. Minha contribuição lida com a região que possivelmente foi palco das sementes históricas de um desses personagens, Saul. Assim, embora talvez insignificante territorial e economicamente no grande quadro do Mediterrâneo antigo oriental, ela é seminal para compreender imaginários reais antigos. Meu objetivo é acessar, mesmo com parcas evidências, conceitos monárquicos presentes na cultura visual do "platô de Benjamin" nos períodos do Ferro IB-IIB. Para tanto, após apresentar o escopo do estudo, apresentarei a configuração sociopolítica e econômica da região, aspectos de representação monárquica no chamado "antigo Israel" para, depois, estudar as fontes visuais arranjadas cronologicamente.

\section{Escopo e objetivos}




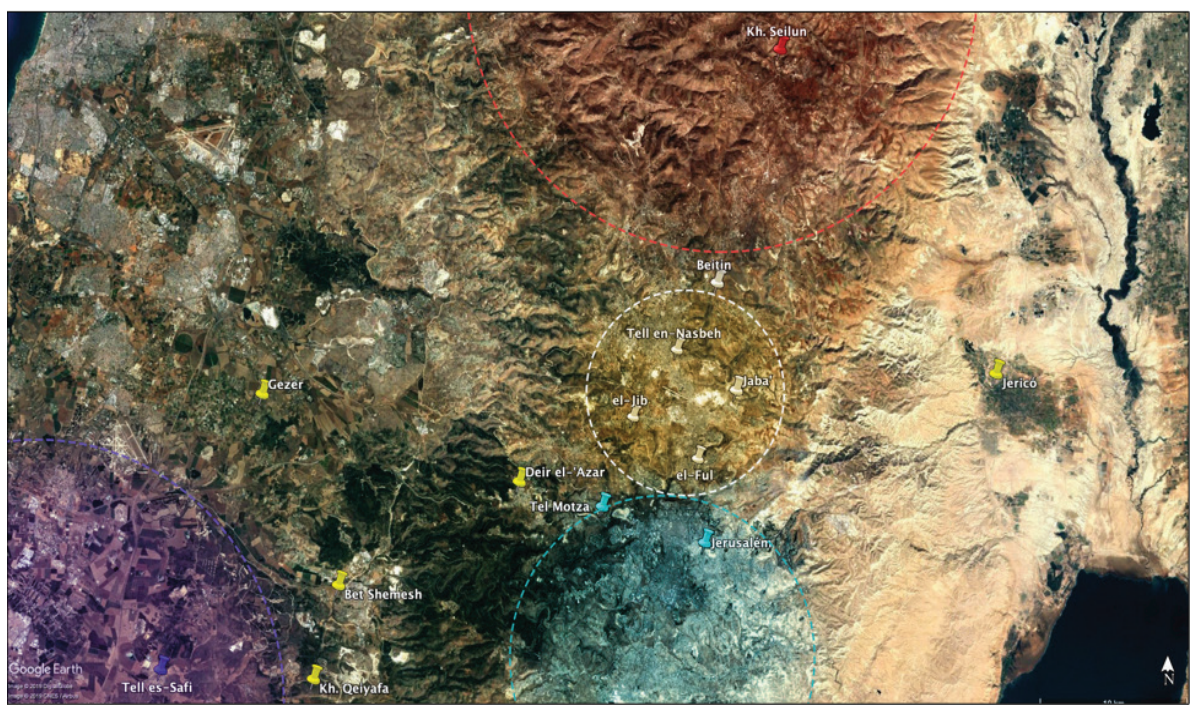

Mapa 1: Platô de Benjamin (amarelo), Judá (azul) e Efraim (vermelho).

Os círculos são apenas reforços ilustrativos, não representam os limites exatos dessas unidades políticas.

Fonte: Autor.

Ocupo-me da área que os textos da Bíblia Hebraica associaram ao lendário patriarca Benjamin (binyamin , cf. Js 18.11-18), esta que prosperou sempre que o poder de seus vizinhos Siquém (Tel Balâtah) e Jerusalém (Al-Quds) desvaneceu, algo evidente no registro bíblico ${ }^{1}$ e arqueológico. ${ }^{2}$ Devido à extensão cronológica do estudo, não utilizo fronteiras políticas, mas as fronteiras naturais e limites de assentamentos do período inicial do Ferro. Assim, o que chamo "platô de Benjamin" se limita pelo Vale de Rift à leste, pela descendente que vai em direção à Sefelá à oeste, pelos limites de Beitin $\left(\right.$ Betel $\left.^{3}\right)$ e et-Tell (Ai?) à norte e, à sul, pela depressão que antecede Jerusalém. Os sítios que divisam a região

1 No texto bíblico, p.ex., isso pode ser visto no momento da "Conquista da Terra" (Js 2-9), no início da monarquia (1Sm 8-13), no exílio judaíta (2Rs 25.22-23; Jr 40.6) e na reestruturação de Jerusalém (Ed 4).

2 Modelos gravitacionais foram aplicados duas vezes na região: (1) Miller II (2005, p. 20, 29-30, 8182) testou a hipótese de "chefaturas complexas" usando a mobilidade de produtos e transferência de tributos entre sítios da região; e (2) Lehmann (2004, p. 158-164) analisou a relação entre as vilas sob o conceito de endogamia. Ambos assinalaram a gravidade populacional maior ao redor do platô. Os levantamentos arqueológicos na região também demonstram o aumento de assentamentos nas cercanias de Betel e Gibeão (FINKELSTEIN; MAGEN, 1993, p. 13-79, 447-52; FINKELSTEIN; LEDERMAN, 1997, p. 891-902).

3 Enquanto prefiro tratar os sítios arqueológicos pelos nomes contemporâneos, assinalo entre parênteses as identificações com sítios bíblicos. Enquanto alguns são tomados por certo pela toponímia (p.ex., Beitin/Betel), evidências epigráficas (p.ex., Tell el-Jîb/Gibeão) ou histórico-geográficas (p.ex., Tell en-Nasḅeh/Mispa; et-Tell/Ai), outros são incertos e, por esse motivo, deixo uma interrogação em suas prováveis identificações. 
são: Jeba (Geba?; 9,6 km NE-Jerusalém) ao leste; Tell en-Nasḅeh (Mispa; 12 km NO-Jerusalém) ao norte; el-Jîb (Gibeão; 9,6 km NO-Jerusalém) ao oeste; Tell el-Fûl (Gibeá?; 4,8 km N-Jerusalém) (cf. Mapa 1).

Como fontes, tomo os vestígios visuais encontrados em escavações controladas, tendo a atenção principalmente voltada ao Ferro IB-IIA antigo. Isso significa que lidarei com achados dos sítios arqueológicos Beitin (Betel), Tell el-Jib (Gibeão), Et-Tell (Ai?), Kh. Abū-Musarrah, Kh. ed-Dawwara, Kh. Nisieh, Kh. Raddana, Tell el-Fûl (Gibeá de Benjamin? Faraton?), Tell enNasḅeh (Mispa). ${ }^{4}$ Contudo, apesar de minha análise sistemática de fundo se restringir a esses sítios e período, ao contrário de trabalhos anteriores focados no Ferro I-IIA (KLEIN CARDOSO, 2019; 2020a; 2020b; 2020c), avanço aqui para períodos posteriores (i.é, Ferro IIB-C), a fim de notar continuidades e descontinuidades na iconografia local. Minha argumentação também considera artefatos de outros sítios sul-levantinos. A mídia mais numerosa e relevante à tarefa são os selos de estampar e impressões (SCHMIT'T, 2001, p. 36) que, embora não forneça "narrativas" stricto sensu, é abundante e ilustrativa o suficiente para o propósito do artigo, que é descrever usos e readaptações da iconografia régia na região.

\section{A configuração sociopolítica de Benjamin no Ferro IB-IIA}

No período do Ferro IB-C é possível vislumbrar padrões arquitetônicos no platô de Benjamin que implicam uma unidade política. Refiro-me aos assentamentos com muralhas acopladas a salas amplas traseiras em

\footnotetext{
Para o histórico ocupacional, cf. FINKELSTEIN, 2015, p. 57-84; MILLER II, 2005, p. 120-22; KLEIN CARDOSO, 2019, p. 177-96; cf. FAUST, 2006. Os sítios El-'Eizariya, El-Qubeibeh, Kh. Hayian, Nebi Samwil, Kh. Shilha não apresentaram resultados relevantes aos períodos investigados. Kh. Qeiyafa, não foi considerada - a despeito da hipótese de domínio de Saul da região no período do Ferro I-IIA por Finkelstein - pela distância, enquanto Moẓa e Deir el-'Azar (Kh-Jearim) não foram exploradas sistematicamente pelo estado inicial das escavações. Sobre o último, veja o relatório preliminar em FINKELSTEIN; RÖMER, 2019.

5 O conceito de narrativa está, na narratologia clássica, ligado à mídia verbal e sob clausuras tempo-espaciais. Assim, uma cena isolada como as que figuram na maioria dos selos de estampar, não se configuraria como narrativa. Novas definições de narrativa, principalmente advindas de estudos de multimodalidade, trazem conceitos mais abertos de narrativa. Marie-Louise Ryan (2006, p. 8), p.ex., divide as "condições de narratividade" em três dimensões semânticas e uma pragmática. Semanticamente, narratividade existiria quando (1) há noção de espacialidade, i.é, trata de um mundo habitado por indivíduos, (2) temporalidade, i.é, quando esse tempo está situado no tempo e passa por transformações e (3) cognição, i.é, os agentes são causados por agências com consciência e capacidade de tomar decisões. Pragmática e formalmente, a narratividade seria possível quando os eventos têm relação de causa e efeito ou quando a história comunica algo para os receptores. Se pensarmos na definição "escalonada”, i.é, não dualista como ela sugere, é possível pensar nas cenas dos selos como "narrativizantes", contudo, essa não é uma característica formal dos objetos.
} 
casas de três ou quatro cômodos encontradas em el-Jîb (FINKELSTEIN, 2015, p. 59; PRITCHARD, 1964, p. 35, fig. 19, 21; 1963, fig. 1), Tell enNasbeh (McCOWN, 1947, p. 180, fig. 43; ZORN, 1993, p. 23), et-Tell (Fonille “Z”, FINKELSTEIN, 1988, p. 69; MARQUET-KRAUSE, 1949, pl. XCVII), nas recém-fundadas Kh. ed-Dawwara (Area A, FINKELSTEIN, 1990, p. 172) e Kh. Raddana (LEDERMAN, 1999, p. 149), além de, possivelmente, Betel (KELSO, 1968, p. 36, pl. 86; 1993, p. 193). Também é significativo que os outros três sítios escavados ou não tiveram escavações em todo o sítio (El-Fûl, FINKELSTEIN, 2011; Abū-Musarrah, cf. PELEG; YEZERSKI, 2004) ou seguiram o modelo do Período do Bronze (Nisieh, LIVINGSTONE, 2012, p. 47-496). Enquanto o padrão de construção de casas não oferece novidades arquitetônicas para o período, a instalação de casamatas, mesmo se não oriunda da região, é majoritária. Em segundo lugar, as práticas mortuárias da região sugerem uma aristocracia rural (LEHMANN; VARONER, 2018, p. 261), como se pode ver nas coleções funerárias encontradas nas tumbas de Khirbet Abū-Musarrạ̣ (PELEG; YEZERSKI, 2004), Khirbet Nisieh (Tumba 65, LIVINGSTONE, 2012, p. 51-64; cf. BRANDL, 2002), el-Jîb (Tumba 3, cf. DAJANI, 1953; PRITCHARD, 1963, p. 10; ESHEL, 1987, p. 10-11) e Tell en-Nasbeh (tumbas 32 e 54, McCOWN, 1947, p. 77-100).

Há de se considerar que o clima e práticas agrícolas da região cooperavam para cultivo e centralização. Quando comparada com a região ao norte de Samaria e Judá, Benjamin possui um clima intermediário (FINKELSTEIN, 1994, p. 158), contudo, pela menor altitude, as colinas de Betel têm menos chuva que as montanhas judaítas (MILLER II, 2005, p. 60). As encostas sul-ocidentais tinham abundância de oliveiras e, possivelmente videiras, mais que as demais regiões, enquanto a extensão central sul, mais próxima de zonas áridas a leste, tinha predominância de cultivo de cereais a leste e criação de animais, especialmente ovelhas e caprinos a oeste, embora de forma limitada (FINKELSTEIN, 1997, p. 117). Eles cultivavam lentilhas, alfafa, grão-de-bico e feijão-de-bico, além do vinho e azeitonas, algo que se confirmaria pelas ferramentas de cultivo de cereal de Kh. Raddana, que também apresentou ossos de caprinos em todas as casas (MILLER II, 2005, p. 60). O padrão altera-se no Ferro II, quando arbustos passam a crescer nas áreas de erosão, antes ocupadas pela floresta (LEV-YADUN, 1997, p. 88-101). Há também alteração no padrão de assentamento: no Ferro I 74\% dos sítios estavam a

É possível argumentar a existência de assentamento no período pela cerâmica encontrada, similar à Beitin (LIVINGSTONE, 2012, p. 48-49, pl. 4.1:7, 9, 15; cf. KELSO, 1968, pl. 56-57; FINKELSTEIN; SINGER-AVITZ, 2009, p. 37-38), quanto pela Tumba 65, do período (BRANDL, 2002). 
leste, na região árida, algo que se modifica no Período do Ferro II. ${ }^{7}$

Essa configuração coaduna com o modelo de governo sugerido por Robert Miller II (2005, p. 8-13). Este sistema sociopolítico compreenderia: (1) a movimentação de tributos para favorecimento mútuo, apesar da autossuficiência das unidades políticas menores (vilas/vilarejos); (2) alternância entre dois ou três níveis de poder a cada 15 anos e a cada 150 anos com novas dinastias; (3) sacralização dos líderes para atender a linhagens ancestrais legitimatórias. Esse ambiente seria reforçado pela instituição de alianças matrimoniais rurais (LEHMANN, 2004), estas que, além dos limites das vilas e comunidades locais (i.é, a bíblica bêt-'āb, “casa do pai"), estariam ligadas por casamentos endogâmicos, o que formariam os clãs territoriais (i.é, a bíblica mǐ̌pāhâa; cf. LEHMANN, 2004; 2012). Esse modelo se manteria até o Ferro IIA, quando os sítios da região são abandonados ou destruídos. Após a derrocada, a pertença de Benjamin teria se modificado para sul e norte, até que, após a destruição de Jerusalém, teria se tornado novamente uma região proeminente e, no quinto século aEC, Mispa foi não apenas parte, mas capital de Yehud (cf. LIPSCHITS, 2005, p. 149-54).

\section{Aspectos fugidios da interpretação da realeza no "antigo Israel"}

O fato de a região não apresentar uma formação estatal stricto sensu nesse período não significa que ideias régias ou monárquicas não tenham sido recebidas e/ou trabalhadas nas narrativas e iconografia local. Isso se explica tanto iconográfica quanto filologicamente. Com relação à memória bíblica, o substantivo hebraico para rei, mělěk , denota um indivíduo que rege um grupo de subordinados e, portanto, a ideia de realeza que repousa sobre os termos melûk $\underline{a}(h)$, mǎlk ût ou mămlāk $\underline{a}(h)$ servem para diversas formatações de governo, desde cidades-estado até impérios (PIETSCH, 2014). Decerto, isso não significa que os temos sejam equivalentes. Os dois conceitos abstratos mais antigos, p.ex., demonstram diferentes facetas da realeza: (1) melûk $\bar{a}(h)$ designa o status e ofício real (p.ex., 1Sm 10.16;11.14; 14.47; 18.8) enquanto (2) $m a ̆ m l a ̄ k a \bar{a}(h)$ aborda o aspecto funcional da realeza/monarquia como instituição (i.é, domínio, reino, residência, poder) (p.ex., 1Sm 10.18) (SEYBOLD; RINGGREN; FABRY, 1997, p. 359-60). É notável que, embora os conceitos

Finkelstein (1994, p. 160-61) sugeriu duas explicações para essa preferência inicial: (1) no começo do processo de assentamento, com menor número de habitantes, os contingentes populacionais teriam optado por áreas topograficamente moderadas e de agricultura promissora, i.é, a margem desértica, vales intermontanos e áreas planas; (2) no começo do processo de assentamento, os novos habitantes teriam escolhidos áreas mais promissoras segundo seus planos de fundo sócioeconômicos, i.é, pastoris e de agricultura de sequeiros. 
sejam utilizados nas narrativas do benjaminita Saul, os textos bíblicos revelam um uso contestado de termos reais para habitantes da região, algo que reforça a presença de conceitos de realeza. ${ }^{8}$ Ademais, mesmo sob uso contestado, fórmulas dinásticas são aplicadas de forma similar a Davi e Saul, i.é, as expressões bêt dāwid ("casa de Davi”) e bêt $̌ s \bar{a}$ 'ull ("casa de Saul”) (cf. 2Sm 3.1,5).

Reconhecer tais aspectos não torna a interpretação iconográfica livre de problemas. Apesar de propor uma tipologia, ${ }^{9}$ Dominik Bonatz (2009, p. 1) argumentou que a dificuldade de estudar a representação de reis no Levante via iconografia se dá: (1) pelo material disponível na região não ser abundante ou representativo o bastante; (2) por ser difícil distinguir reis de divindades, i.é, por não haver traços iconográficos incontestes ou não-ambíguos; (3) pela dificuldade de assegurar a interpretação de figuras não-antropomórficas aos domínios reais. Em Estudos Bíblicos, comparações dessas imagens com textos e conceitos veterotestamentários foram feitas para resolver este problema. Os dois estudos mais representativos são o de Keel (1997, p. 243-306), ${ }^{10}$ que comparou imagens antigo-orientais com os salmos e o estudo sobre a iconografia de domínio no primeiro milênio de Schmitt (2001). ${ }^{11}$ Outros, como Keel e Uehlinger (1998) e Schroer (2018; cf. SCHROER; KEEL, 2005;

Refiro-me, principalmente, ao uso conflitivo do termo "líder" (nägîd, 1Sm 9.16; 10.1) em certas narrativas saulidas, este que pode ser adição deuteronomista (McKENZIE, 2006, p. 60-62) ou revelar nuances religiosas do ofício. Para Hasel (1998, v. 9, p. 193, tradução minha) “no título 'rei', a ênfase primária está no elemento político, enquanto no título nāg $\underline{\hat{l}} \underline{d}$ os elementos religioso e sagrado permanecem no primeiro plano”. A vocação de Saul, como os juízes (Jz 2.16,18), é de salvar (yš ) com libertação pontual frente aos filisteus (pĕlištî́, cf. 2Sm 3.18). O clamor do povo (1Sm 9.16) é similar ao de Ex 3.7. Os termos clamor (șe '⿳亠 $q \hat{a})$, povo ( 'am) e ver $\left(r^{\prime} h\right)$ só aparecem nesses dois versículos em toda a BH. A palavra clamor (șé $\bar{a} q \hat{a})$, surge apenas $2 \mathrm{x}$ na HD $(1 \mathrm{Sm} 4.14 ; 1 \mathrm{Sm} 9.16)$ e sua raiz, $V_{s}$ ' $q$ apenas outras duas vezes referenciando o Êxodo (Js 24.7; Jz 10.11) e, talvez, demonstrando reminiscências de tradição de Israel (norte). Ademais, a própria botelha utilizada na unção (pak, 1Sm 10.1) só surge nessa narrativa e na unção de Jeú (2Rs 9.1,3), outro líder com missão religiosa. As unções de Davi e Salomão são realizadas com chifres de azeite (qarnĕkà šemen, $1 \mathrm{Sm} 16.1,13$; 1Rs 1.39).

9 Dividida entre figurações antropomórficas e teriomórficas, cada qual com diversos sub-fenótipos.

10 Que dividiu a iconografia real (principalmente egípcia) comparada aos salmos em cinco grandes temas: (1) nascimento e infância do rei; (2) entronização; (3) o rei como construtor do templo e sacerdote; (4) representação e promoção dos poderes da vida; (5) defesa contra os inimigos. O autor ainda trabalhou aspectos de dominação real em outras duas obras, ampliando a discussão (KEEL 1974; 1999).

11 Schmitt (2001, p. 37-38) dividiu a representação pictória dos governantes do Período do Ferro em 6 grupos com diversos sub-grupos: (1) representação do rei, com sete subgrupos, (1a) rei entronizado, (1b) rei com funcionários, (1c) rei com outras insígnias, (1d) rei diante da divindade, (1e) rei com dignatário(s), (1f) rei atacando o inimigo, (1g) rei na carruagem; (2.1) símbolos de poder militar, com três subgrupos, (2.1a) prisioneiros, (2.1b) carruagens, (2.1c) cidade fortificada; (2.2) domínio em contexto vegetal, com dois subgrupos, (2.2a) capitéis de voluta, (2.2b) palmeira e árvore sagrada; (3) animais com quatro subgrupos, (3a) leão, (3b) cavalo, (3c) galo, (3d) outros quadrúpedes; (4) seres mistos e gênios com quatro subgrupos, (4a) grifo, (4b) esfinge, (4c) escaravelho alado, (4d) gênios antropomórficos; (5) símbolos divinos em contexto de domínio com dois grupos, (5a) sol alado, (5b) roseta ou disco solar; (6) outros. Embora o trabalho de Schmitt dê peso maior às fontes iconográficas, a relação de temas está baseada em sua interpretação dos textos bíblicos, não sendo, portanto, uma tipologia puramente iconográfica. 
SCHROER, 2008; 2011) focalizaram a história da religião, trabalhando o tema quando este era relevante à disciplina.

No presente estudo assumo o risco de interpretar as fontes disponíveis sem colocá-las sob a tutela dos textos bíblicos. Apesar de leituras contra o grão serem possíveis e necessárias, penso que a narratividade dessas memórias tardias preencha lacunas desnecessárias e direcione as conclusões de forma indevida em uma pesquisa com escopo limitado como esta. Isso se torna ainda mais relevante ao tentar uma delimitação mais restrita como a que proponho, i.é, focar em conceitos de realeza presente nas fontes iconográficas no Ferro I-IIB, algo não realizado. ${ }^{12}$ Para lidar com as dificuldades do material acima e para atender aos objetivos propostos no dossiê, ao contrário de tentar identificar reis em imagens, apresentarei cenas que tragam conceitos ligados à realeza, para demonstrar ideias que perpassavam a região nos períodos designados. Assim, a seguir, apresento as fontes divididas por período e motivos iconográficos relacionados, e as examino via análise iconográfica para, na conclusão, discutir os resultados.

\section{Conceitos visuais de realeza no platô de Benjamin: um panorama}

\section{O vigor e a filiação divina dos reis (Ferro IB-IIA antigo)}

Durante o período da supramencionada unidade política centrada no platô de Benjamin do Ferro IB-IIA (c. 1050-950 aEC) há três constelações iconográficas relevantes ao tema.

A primeira trata aspectos de dominação e atribuem ao rei vigor, força e poder sobre povos inimigos, esses considerados inferiores. Três peças podem ilustrar esse repertório de conceitos. A fig. 1a apresenta um conóide de basalto encontrado dentre detritos da Area $A$ de Betel com gravura linear e hachura interna (KELSO, 1968, p. 121, pl. 44: 5), este que traz um leão sobre um caprino com cabeça virada para trás. O leão reflete a agressividade e o domínio do rei egípcio sobre seus inimigos (KEEL; UEHLINGER, 1998, p. 21-25, 120-21), figuração vista desde o Bronze Médio e que pode possuir conotações sexuais (SCHROER, 2008, p. 132-35). A mesma figuração agressiva do leão aparece em um selo do grupo chamado "selos produzidos em massa pós-ramessidas (cf. MÜNGER, 2011³) em Gibeão. O escaravelho da fig. 1b foi encontrado levemente danificado na Tumba 3 (PRITCHARD,

\footnotetext{
12 O acesso a um grupo de selos de Tell en-Nasbeheh, de igual modo, é inédito e fruto de meu trabalho no Stamp Seals from the Southern Levant, onde entre outras incumbências trabalho na publicação dos selos do sítio.

13 Além dos selos apresentados aqui, outro selo desse grupo foi encontrado na região, em Kh. Nisieh (BRANDL, 2002, p. 40-42, no. 3), com rosetas e uraei na base. Embora também ligado, em certo aspecto, ao âmbito real, optei deixá-lo de lado pelo número limitado de achados no período.
} 
1963, p. 154, fig. 70.5) e apresenta um leão em marcha esquemático com o rabo sobre as costas do animal e apontando para a frente (paralelos em KEEL; UEHLINGER, 1998, p. 112, figs. 133a-f). Do mesmo grupo pós-ramessida, também apresentando o mesmo campo de dominação por força está a fig. 1c, um escarabóide de ibex encontrado na Tumba 32 de Tell enNasḅeh (McCOWN, 1947, p. 149, pl. 54: 34) que tem na base Resefe sobre uma gazela (mas veja a opinião de $\mathrm{KOCH}, 2018$, p. 643). A iconografia de Baal sobre o leão e Resefe sobre a gazela parece ser completada por outra imagem encontrada no sítio (SCHROER, 2018, p. 344). A impressão em alça de jarro (McCOWN, 1947, pl. 55: 81) da fig. 1d, que, pelo formato, parece vir da lateral de um selo decorado multifacetado, apresenta figura antropomórfica com um objeto não identificado na mão e, abaixo dela, um pequeno sol, um leão e montanhas. Essas duas últimas cenas relacionam-se à realeza por sua associação ao deus-rei (cf. discussão da fig. 3c, a seguir).

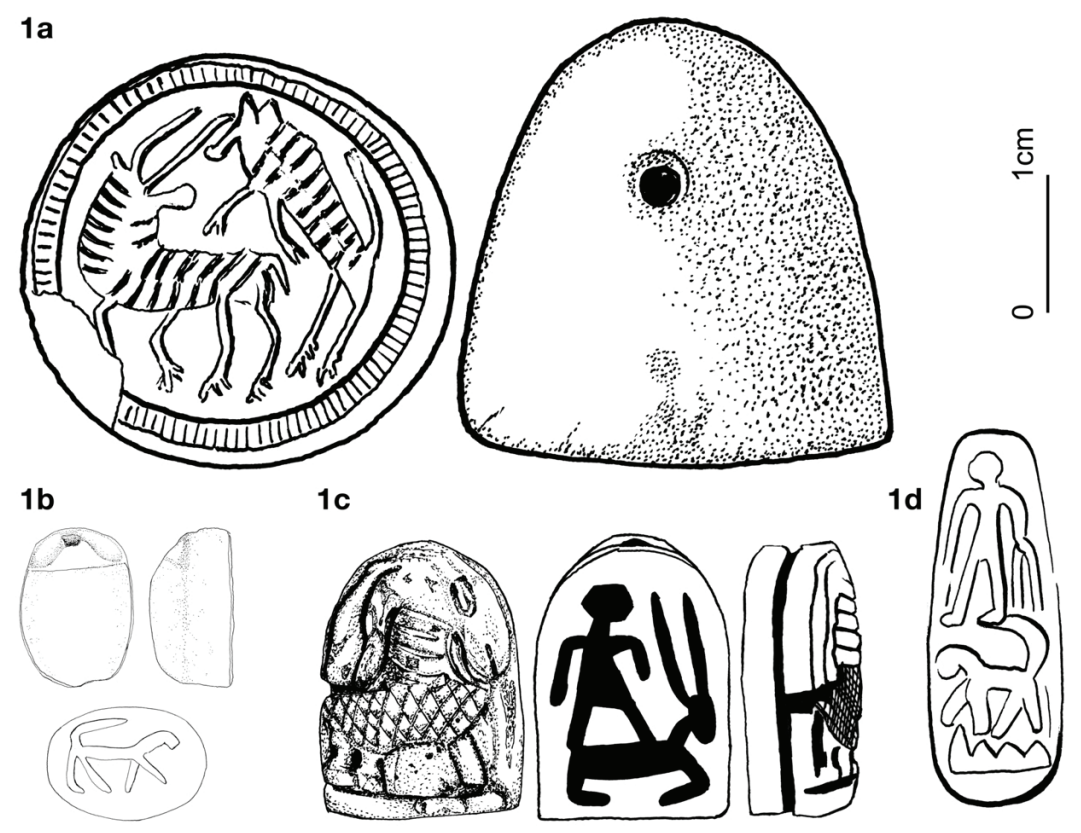

Figura 1: Fonte: (a) KEEL, 2010a, p. 22-23, Bet-El No. 7; (b) KEEL, 2013, p. 476-77, Gibeon, No. 26; (c) KEEL, 1995, Abb. 90; (d) KEEL; SHUVAL; UEHLINGER, 1990, p. 139.

A segunda constelação aborda a entronização e a deificação do rei, muitas vezes pressupondo que a autoridade do rei advenha de sua 
filiação divina. Desses, o mais emblemático é o escarabóide da Tumba 32 de Tell en-Nasḅeh (McCOWN, 1947, p. 295, pl. 54: 18), que aparece na fig. 2a. Do lado direito, uma figura esquemática com braços erguidos está assentada sobre um trono e, próximo a sua mão direita, um vegetal completa o perfil. $\mathrm{Na}$ frente dessa figura está em pé uma segunda figura antropomórfica. Há ao menos três formas de interpretar a cena: (1) um casal divino e um adorador (KEEL; UEHLINGER, 1998, \95, onde as deidades são interpretadas como El no trono e Aserá em forma de árvore estilizada); (2) uma divindade com flor de lótus na mão e um adorador (KLEIN CARDOSO, 2019, p. 244-45, onde a deidade é interpretada como Baal); (3) um rei com flor de lótus na mão e um convidado e/ ou adorador. Enquanto as três interpretações são possíveis ou, talvez, se sobreponham, é interessante pensá-la aqui em relação com outras cenas, como o sarcófago de Abirão em Biblos. Nesse caso, enquanto a flor de lótus representaria a vida do rei, o adorador ou rei demonstraria a elevação da figura no trono a um patamar sobre-humano, reinterpretando temas do Bronze Tardio como "o rei com a flor de lótus" e o "governante e adorador". É possível que a fig. 2b, uma impressão de selo de Betel (KELSO, 1968, pl. 114:12) também traga um rei no trono e adorador. Apesar de não ter sido reconhecida como tal até o momento, o traçado inferior do selo parece similar às bases do trono na cena bastante estilizada de entronização no palácio, também comum na produção em massa de selos pós-ramessida (cf. paralelo em SCHROER, 2018, p. 152-53, no. 1043). Nessas cenas, o rei, assentado em seu trono palaciano, é adorado por seus servidores e traz em suas mãos o cetro e uma cruz. Também apontando para o aspecto sobrenatural do rei, embora com diferente figuração, temos a figura antropomórfica com cabeça de falcão, identificado como Hórus, e a pena de Maat. Enquanto a iconografia de Hórus lembrava a filiação divina do rei desde o Bronze Antigo e chegou, no auge de popularidade do Bronze Tardio, a ser fundido com o deus do clima cananeu (SCHROER, 2011, p. 46), essa característica aparentemente foi perdida no Período do Ferro. O escaravelho pós-ramessida representado pela fig. 2c encontrado na Tumba 32 de Tell en-Nasbeh (McCOWN, 1947, pl. 54:5), contudo, ainda traz a imagem, demonstrando o uso do tema no período. 


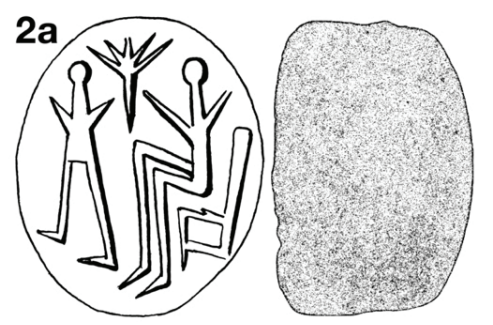

$2 b$
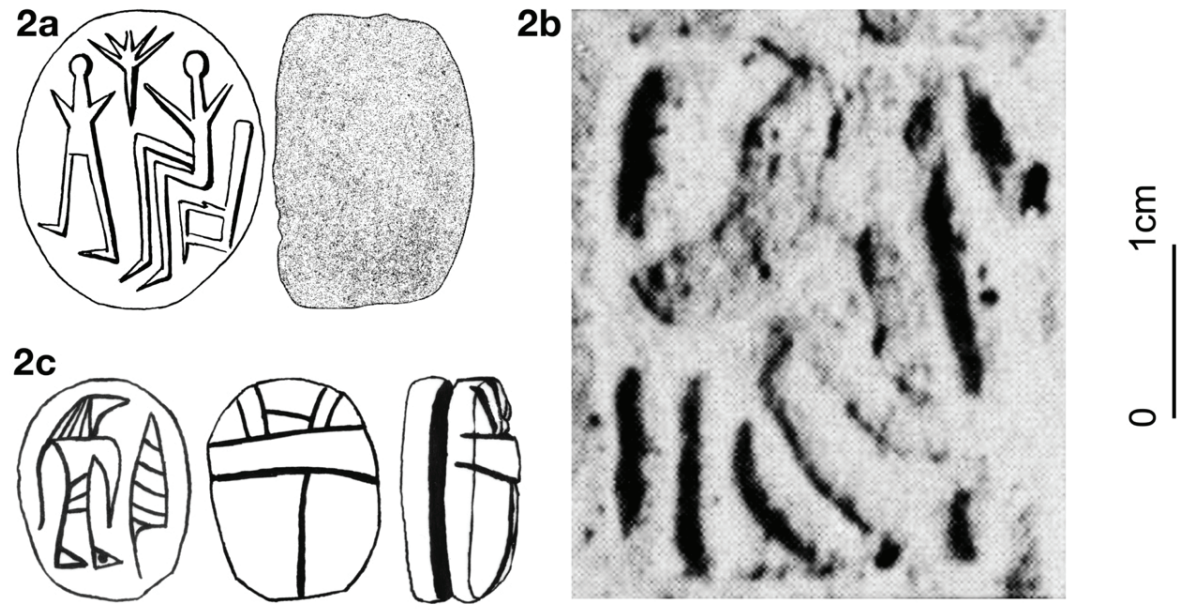

Figura 2: Fonte: (a) KEEL; UEHLINGER, 1998, fig. 181;

(b) KELSO, 1968, pl. 114:12; (c) MÜNGER, 2011, Pl. XLVII: Tell en-Nasbeh No. 1.

Uma terceira constelação reutiliza a iconografia de coroação egípcia dos períodos anteriores e que foi possivelmente utilizada no culto. Enquanto cenas explícitas da veneração ao rei não surjam no Período do Ferro I-IIA antigo com a mesma intensidade do Bronze Tardio, cartuchos com nomes reais e criptogramas do deus-rei egípcio, Amon, continuam a ser utilizadas (SCHROER, 2018, p. 63) e aparecem na região. A fórmula mais comum no registro local é aquela que pode ser lida como menkheperre (mn-hpr-R $R^{\varsigma}$, poss., "permanente é a forma de Rá”), utilizada como nome de trono de Tutemés III, mas cujos selos foram também utilizados no culto de Amon. Do repertório de Tell en-Nasḅeh, também encontrado na tumba 32 (McCOWN, 1947, pl. 54:11), o escaravelho da fig. 3a traz a expressão $m n$ (tabuleiro de senet, Y $5^{14}$ ), hpr (escaravelho, L1), $R^{\varsigma}$ (círculo solar, N5). O mastro com bandeirola (R8) serve como determinativo para divindade. A fórmula, escrita sob diferentes grafias, aparece outras vezes na região (p.ex., McCOWN, 1947, pl. 54:10, 14, 16). A escrita, provavelmente relacionada ao deus-rei Amon-Rá, é paralela com outro selo que traz o nome de Amon escrito criptograficamente. O escaravelho da fig. 3b, também do grupo pós-ramessida produzido em massa, foi encontrado também na Tumba 32 (McCOWN, 1947, pl. 54:13) e forma "Amon-Rá" (Jmn-R ${ }^{\uparrow}$ ): a coroa vermelha em ambos os lados é lida acrofonicamente como um $J$

14 Os números entre parênteses apontam para a lista de Gardiner de hieróglifos. 
(do egípcio jns), esta que é combinada, de cima abaixo, com o tabuleiro de senet ( $m$ n, Y5) e o falcão com o flagelo, este lido como $R^{\varsigma}$ (JAEGER, 1982, p. 294; cf. SCHROER, 2018, p. 162-63, No. 1057). Possivelmente ligados ou resultantes da popularidade do culto ao deus Amon em Gaza (cf. UEHLINGER, 1990), as cenas ainda podem estar ligadas a um terceiro motivo, que são o de três figuras antropomórficas de mãos dadas, que surge no selo de Gibeão encontrado na Tumba (PRITCHARD, 1963, p. 154, no. 2) e representado pela fig. 3c. A cena já foi interpretada como uma variação canaanita da tríade divina e como dança, mas sua presença em selos multifacetados parece reforçar o caso da primeira interpretação (veja KOCH, 2018, p. 639-40). Caso isso esteja correto, a aparição da tríade divina, de temas ligados a Amon-Rá (fig. 1b, 3a-b), Resefe (fig. 1c) e Set (i.é, Baal em Canaã, fig. 1d), todos estes que surgem em selos multifacetados/ pirâmides truncadas, pressuporiam o ambiente de corte e ideologia régia.

3a

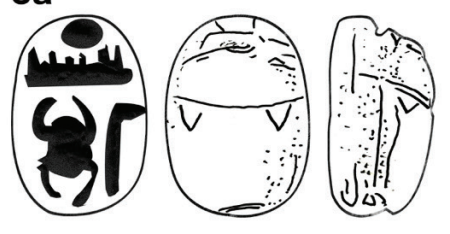

3b
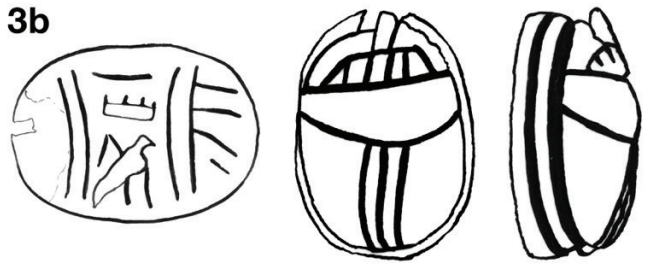

3c
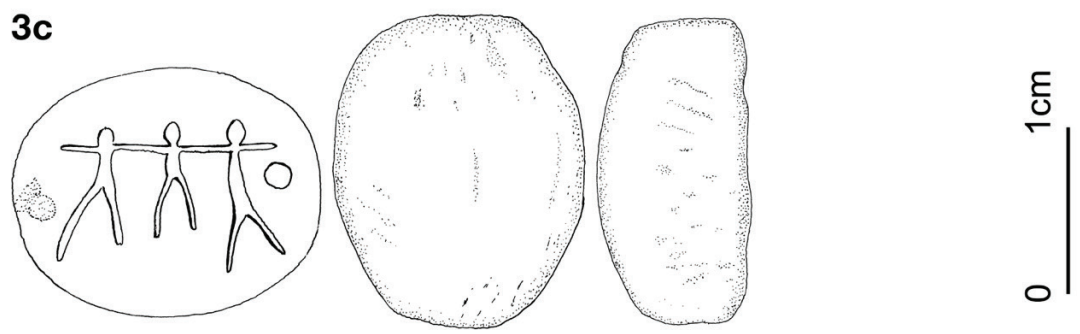

Figura 3: Fonte: (a) Ilustração do autor; (b) MÜNGER, 2011, Pl. XLVII: Tell en-Nasbeh No. 2; (c) KEEL, 2013, p. 474-75, Gibeon no. 23.

Agressividade e perfil vitorioso dos reis (Ferro IIA tardio-Ferro IIB)

Apesar da configuração sociopolítica distinta, onde não há mais uma chefatura tentando se estabelecer a partir da região, o Ferro IIA tardio e Ferro IIB continuam a apresentar simbologia régia. Esses, contudo, já carregam um sotaque regional. Isso é visto na utilização de hieróglifos, agora funcionam mais como símbolos de poder deslocados do contexto linguístico 
original (i.é, seriam pseudo-hieróglifos). ${ }^{15}$ Devo enfatizar que, pelas mudanças no quadro político, o platô de Benjamin na época dos selos abaixo (sécs. 7-6 a.E.C.) está mais próximo de Judá do que de Israel. ${ }^{16}$ Isso também é visto na iconografia, que traz temas mais de mesma orientação. Dois grupos iconográficos ligados ao reino animal são importantes.

Dois selos da região apresentam galos como motivo iconográfico central. O primeiro item ${ }^{17}$, provavelmente um conóide ${ }^{18}$ retratado na fig. $4 \mathrm{a}$, infelizmente, não possui boas fotos da base e precisamos contar com a descrição do arqueólogo responsável que a descreveu como "duas figuras animais lutando (provavelmente galos)" (DAJANI, 1953, p. 74, tradução nossa). Galos aparecem outras vezes na região em diferentes mídias, como em inscrições em jarros (PRITCHARD, 1961, p. 20, fig. 47: 305, 399, 343, 492) e em uma estatueta de Horvat Qitmit (BECK, 1995, fig. 3.94). A agressividade e defensibilidade do galo, estas vistas principalmente em brigas de galo, o tornam ideal para representar servidores reais e pessoas da corte (SCHMITT, 2001, p. 169). Isso é demonstrado no selo epigráfico de ágata encontrado em Tell en-Nasbeheh (McCOWN, 1947, pl. 57:4-5) e representado na fig. 4b. A base tem três registros divididos por linhas duplas. Nas duas primeiras linhas, é possível ler o texto hebraico antigo ly 'zny $h w /{ }^{\prime} b d . h m l k$, "Pertencente a Jezanias ${ }^{19}$ servo do rei”. Na última linha há um galo virado para a esquerda em posição de ataque: a cabeça pende para a frente, seu bico está aberto, as asas estão presas ao corpo antes da longa cauda e as pernas uma em frente à outra, sugerindo movimento. Devo enfatizar que a inscrição associa o selo diretamente à corte, o que reforça a hipótese de se tratar de iconografia do

15 A pesquisa de Laura Gonnermann (2021) sobre uso de hieróglifos em amuletos sul-levantinos é particularmente relevante aqui. Ela demonstra que o número de amuletos com hieróglifos aumenta no Ferro II, algo inversamente proporcional ao domínio egípcio na região (p. 83). Ela associou os amuletos ao ciclo de vida dos habitantes da região (p. 87), estes que não careciam de alto poder econômico ou status para usufruí-los. Importante também é sua anotação que os hieróglifos eram uma "língua de escolha", já que o hebraico estava mais disseminado e havia outros artefatos inscritos no período.

16 Devo ressaltar, contudo, que há flutuações nos limites de Benjamin no período e que, possivelmente, até os anos da queda de Jerusalém, o platô tendia mais ao norte. Essa memória é registrada em alguns textos e certos aspectos da iconografia real judaíta, assim como a memória literária, também assumiram partes do imaginário do norte. Isso pode ser visto, por exemplo, na utilização da iconografia local para inspiração de complexos textuais que narram a queda de Israel, como demonstrei em outro local (KLEIN CARDOSO, 2018).

17 Não é possível, pela informação disponível do relatório de Dajani, traçar a data para o item além do contexto primário, que provavelmente reflete a transição do Ferro IIA antigo para o Ferro IIA tardio. Tampouco é possível fazer suposições tipológicas. O agrupo nesta sessão, portanto, pela relação temática.

18 Keel (2013, p. 466) o descreve como placa redonda. Contudo, a sombra da perfuração e volume do objeto na foto da publicação, sugerem a verticalidade da peça (cf. DAJANI, 1953, pl. X: 61).

19 A grafia desse e demais nomes foi aportuguesada cf. versão portuguesa Almeida Revista e Atualizada. 
âmbito régio. ${ }^{20} \mathrm{O}$ famoso selo foi, provavelmente, utilizado como herança familiar: embora a iconografia e a epigrafia apontem para sua produção no Período do Ferro IIB (sécs. 7-6 a.E.C.), ele foi encontrado numa tumba bizantina, esta provavelmente adaptada de uma tumba mais antiga do Ferro II (ZORN, 2003, p. 441).

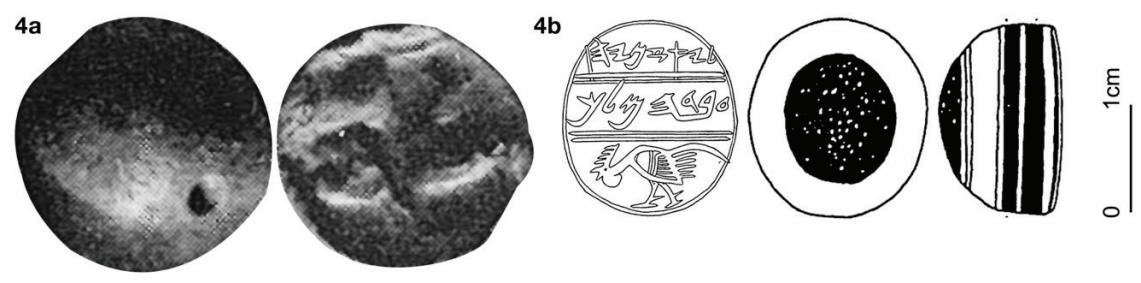

Figura 4: Fonte: (a) DAJANI, 1953, pl. X: 61 (tratadas pelo autor, escala aproximada); (b) BADÈ, 1933, pl. 1.

O último motivo que farei referência é, também, o mais emblemático da relação de Judá com a monarquia. Refiro-me aos selos que retratam leões em posição de marcha e rugindo. A figura mais proeminente é de um escarabóide encontrado no Silo 170 de Tell en-Nasbeheh (McCOWN, 1947, pl. 55:75), representado na fig. 5a. Ele apresenta um leão marchando e rugindo virado à direita com uma cauda comprida e erguida em estilo antigo-oriental, ${ }^{21}$ estando rodeado por sinais egípcios: atrás um ' $n h$ ( $(\mathrm{S} 34)$, acima um $n b(\mathrm{~V} 30)$ e em sua frente cetro-w3s de cabeça para baixo (S40). Enquanto sinais egípcios ao redor de um animal vigoroso geralmente apontam para uma personalidade régia, ${ }^{22}$ a cena, como um todo, retrata o leão como guardião atrelado às esferas de poder, dominância e reinado (cf. KEEL; UEHLINGER, 1998, \ 118, \158; SCHMITT, 2001, p. 121-26; SCHROER, 2018, p. 78, 81). O motivo é similar ao de outro famoso selo epigráfico de "Shemá, servo de Jeroboão", encontrado

20 Outro achado relevante é o selo comprado em Jerusalém com o texto “ $y h w$ ' $h q / b n$. $h m l k$ ”, que poderia ser traduzido como "Pertencente a Joacaz, filho do rei". Contudo, além de não ter advindo de escavações controladas, há partes de pátina sobre a escrita e o artesanato é de má-qualidade (AVIGAD; SASS, 1993, p. 54, no. 13). Além disso, a posição do galo estranhamente segue o fluxo contrário do texto. Esses aspectos sugerem ser uma falsificação. Mesmo que não seja, contudo, Avigad e Sass (1993, p. 467 , bn hmlk) explicam que "filho do rei” pode ter sido utilizado como metáfora de vassalagem, representando um oficial real.

21 Enquanto leões aparecem com a boca fechada na iconografia egípcia, os ombros sobressalentes, juba grafada com movimento e boca aberta remete aos selos encontrados no antigo-oriente (SCHROER, 2018, p. 618). Kurt Galling (1941, p. 136-37) notou a similaridade desse tipo de figuração leonina com selos fenícios.

22 Isso pode ser argumentado também por paralelos que tomam cavalos (p.ex., SCHROER, 2011, p. 98-99, No. 589) ou esfinges (p.ex., BEN-TOR, 2007, pl. 100-101) como personificações dos faraós. 
em Megiddo. ${ }^{23}$ Outro leão rugindo e com a cauda acima do corpo, embora agachado, aparece no registro inferior do escarabóide representado pela fig. 5b e encontrado na Room 174 de Tell en-Nasbeh (McCOWN, 1947, pl. 54: 52). No registro superior um falcão com flagelo (G6) é acompanhado por um ' $n h$ (S34). A combinação peculiar de motivos parece sugerir a dupla lealdade política do portador do selo de forma anicônica. Enquanto o falcão com flagelo e 'nh, que seria lido como "Hórus vivo", pode significar a lealdade ao soberano egípcio - este muitas vezes retratado como o falcão de hórus ${ }^{24}$-, como alguns selos epigráficos que usam o motivo parecem argumentar (KEEL, 2007, \695), ${ }^{25}$ a combinação com o leão sugere relação com o campo semântico de poder e realeza, possivelmente ligado a uma personalidade local. ${ }^{26}$
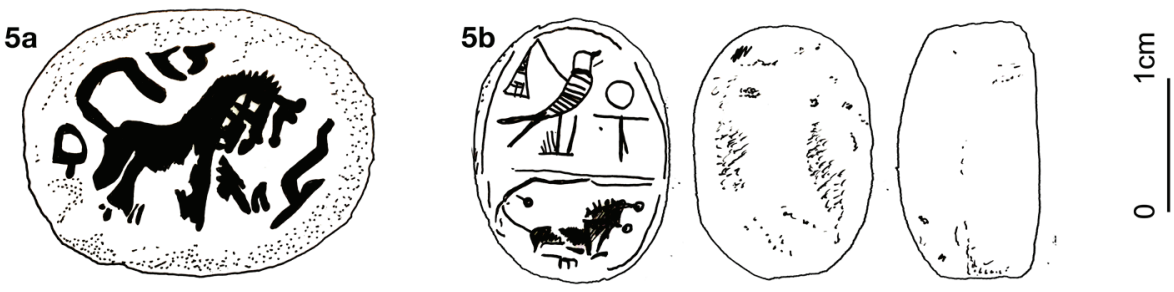

Figura 5: Fonte: (a) Ilustração do autor; (b) Ilustração do autor.

Essa última variação de motivos acima antecipa um tema favorito do Ferro IIC, quando um sistema administrativo judaíta passa a vigorar. Esse modelo inclui as estampas em jarras de alça com leões, estes que podem estar em posições distintas (veja, recentemente, ORNAN; LIPSCHITS, 2020) e que funcionaram ao lado de outras impressões como, p.ex., as impressões yhwd, de cavalos galopantes e rosetas, essas também encontradas em Tell en-Nasbeh. Nesse aspecto, parece razoável argumentar que a mudança de pertença de

23 Embora tenha sido roubado e não mais poder ser analisado, o selo traria originalmente, também, um ' $n$ h.

24 Estes que já aparecem na iconografia do Ferro IIA da região, mas não puderam ser incluídos aqui. Refiro-me aos selos de Tell en-Nasḅeh (McCOWN, 1947, pl. 54:56) e Gibeão (DAJANI, 1953, pl. X:61).

25 Zorn (2018, p. 74) nota que haveria múltiplas razões para os babilônios terem poupado Benjamin, como a longa antipatia local à dinastia davídica ou para utilizarem a região para mantimentos durante o cerco e como centro administrativo depois. De qualquer forma, ainda que reduzida, a região continuou ocupada no período.

26 Uma hipótese recente afirma que o leão sozinho em figurações judaítas representaria $y h w h$ (ORNAN; WEKSLER-BDOLAH; KISILEVITZ; SASS, 2012, p. 6-8; cf. ORNAN; LIPSCHITS, 2020) algo que, talvez, tenha sido utilizado por textos posteriores (KLEIN CARDOSO, 2018). Contudo, em contraposição a essa ideia está o fato de selos de outras regiões sem yhwh e, também, de contextos régios, trazerem figurações similares. Essa relação pode ser vista já na seleção de paralelos feita por Galling (1941, p. 136-37, 175-76, Taf. 5: 17-29): além do selo de Jeroboão (no. 17), o selo no. 20 foi encontrado no palácio de Sargão e o no. 25 também carrega a função "servo do rei" ( $b d m l k$ ). Se a hipótese da dupla filiação for correta, isso explicaria a recorrência do motivo no sítio arqueológico. 
Benjamin entre os períodos do Ferro IIA tardio, IIB e IIC tenha ajudado preferências iconográficas israelitas entrarem em Judá. Assim, a característica fronteiriça da área lhe traria o encargo de tradutora cultural.

\section{Perspectivas conclusivas}

Procurei demonstrar no breve estudo acima como as chefaturas locais utilizaram e reinterpretaram a iconografia régia dos impérios que dominaram a região no passado e como essas reinterpretações pavimentaram a iconografia administrativa posterior. É verdade que as evidências fragmentárias e a falta de resolução cronológica não permitem grandes asserções. Isso está ligado às decisões metodológicas que desenharam o estudo. A decisão por utilizar apenas evidências primárias — i.é, datadas por critérios arqueológicos - e a opção por trabalhar com uma área e tempo restritos faz com que complexos textuais tardios não preencham as lacunas e, assim, os resultados parecem apontar para conceitos sem uma narrativa que as ordene. Apesar deste aspecto, algumas conclusões provisórias podem ser esboçadas. Em primeiro lugar, é possível sugerir certas relações do contexto dos achados com o estrato social ao qual pertenciam. Apesar de não ser possível argumentar conclusivamente que esses vestígios representem os chefes locais, lideranças políticas estrangeiras, deidades ou clãs, ${ }^{27} \mathrm{O}$ fato de muitos desses selos terem sido encontrados em contextos funerários (Figs. 1b-c; 2a, c; 3a-c; 4a-b) diz algo. Estas tumbas muito provavelmente pertenceram a uma "aristocracia rural" e, dessa forma, é razoável sugerir que esses materiais e sua iconografia estavam ligados de alguma forma à biografia dos falecidos da região e refletem, em algum aspecto, sua cosmovisão.

Parece também razoável concluir que, durante o Período do Ferro I-IIA antigo, a proximidade com o Egito fez com que noções de filiação divina dos reis e aspectos de domínio fossem utilizados (Fig. 1b; 2b-c; 3a-b) ou reinterpretados localmente (Figs. 1a, c, d; 2a). Contudo, haja vista a complexa trama política de fim de dominação local, é difícil assinalar lealdades ou pertenças políticas particulares no contexto. O que se pode dizer é que as figuras reais surgiam no imaginário tanto como provedoras da vida (Fig. 2a), quanto como herdeiras do poder divino (Figs. 2b [?] e 2c). A dominação surge tanto na metáfora militar/sexual encontrada no selo de Beitin (Fig. 1a), quanto na

\footnotetext{
${ }^{27}$ Faço eco proposital a Sass (1993, p. 222, tradução nossa): “o que o leão representava para os olhos de Shema, oficial do rei Jeroboão II e para outros proprietários de selos? Ele tinha um significado diferente para não-israelitas contemporâneos? Não está nada claro se esses leões solitários representavam apenas seu próprio poder natural ou apotropaico como leões guardiões ou se eles representavam o rei ou uma deidade".
} 
figuração do leão em marcha e rugindo (Fig. 1b). A associação com deuses também parece indicar indiretamente tanto a influência egípcia quanto uma cosmovisão que os via compondo uma corte (Fig. 3c). Entre o Ferro IIA tardio e o Ferro IIB, a iconografia ligada à violência, à agressividade e ao perfil vitorioso dos reis parece tomar o centro da arena. Isso é visto em selos que trazem emblemas de famílias locais proeminentes, como o galo de briga e o leão. As cenas de galos de briga, como no selo do servo real, Jezanias (Fig. 4b), e, provavelmente, em um selo de Gibeão (Fig. 4a), parecem trazer a ideia de agressividade. O leão, outro animal territorial e agressivo, parece representar o perfil vitorioso de líderes locais (Fig. 5a-b). Sua representação marchando e rugindo como dos selos, entre outras, foi adotada como emblema do sistema administrativo posterior, como parecem argumentar as estampas figurando leões, ao lado de outras utilizadas nos arredores de Judá.

\section{Referências bibliográficas}

AVIGAD, N.; SASS, B. Corpus of West Semitic stamp seals. Jerusalem: IES; HUJI, 1997.

BADÈ, W. F. The seal of Jaazaniah. ZAW, v. 51, p. 150-156, 1933.

BARSTAD, H. M. "DOD דוד". In: TOORN, K V. D.; BECKING, B.; HORST, P. W. V. D. (orgs.). Dictionary of deities and demons in the Bible. Leiden; Grand Rapids, MI: Brill; Eerdmans, 1999, p. 259-262.

BECK, P. Catalogue of cult objects and study of the iconography. In: BEITH-ARIEH, I. (ed.). Horvat Qitmit: an Edomite shrine in the biblical Negev. Tel Aviv: Tel Aviv University, 1995, p. 27-208. (Monograph Series of the Institute of Archaeology of Tel Aviv University, 11).

BEN-TOR, D. Scarabs, chronology, and interconnections: Egypt and Palestinein the Second Intermediate Period. Friburgo, Suíça; Göttingen: Academic Press Fribourg; Vandenhoeck \& Ruprecht, 2007. (OBO.SA, 27).

BONATZ, D. King (Levant). In: EGGLER, J.; UEHLINGER, C. (eds.). Iconography of deities and demons: an iconographic dictionary with special emphasis on First-Millennium BCE Palestine/Israel. Zurique: Universidade de Zurique; SNSF, 2009. Disponível em: http:// www.religionswissenschaft.uzh.ch/idd/prepublications/e_idd_king_levant.pdf. Acesso em: 15/06/2021. [Pré-publicação eletrônica].

BRANDL, B. A Dagger Pommel, two scarabs and a seal from Tomb 65 at Khirbet Nisya. Atiqot, v. 43, p. 37-48, 2002.

DAJANI, A. K. An Iron Age tomb at al-Jib. $A D A J$, v. 2, p. 66-74, 1953.

DIETRICH, W. The Early Monarchy in Israel: the tenth century BCE. Atlanta: SBL, 2007.

EHRLICH, C. S. (ed.). Saul in story and tradition. Tübingen: Mohr Siebeck, 2006.

ESHEL, H. The Late Iron Age cemetery of Gibeon. Israel Exploration Journal, v. 37, p. 1-17, 1987.

FAUST, A. Settlement patterns and State formation in southern Samaria. In: EHRLICH, C. S. (ed.). Saul in story and tradition. Tübingen: Mohr Siebeck, 2006, p. 14-38. (FAT, 47). 
FINKELSTEIN, I. Ethno-historical background: land use and demography in recent generations. In: FINKELSTEIN, I.; LEDERMAN, Z. (eds.). Highlands of many cultures: the southern Samaria survey. 2 vols. Tel Aviv: Institute of Archaeology of Tel Aviv University, 1997a, 109-130. (SMNIA, 14).

FINKELSTEIN, I. Excavations at Khirbet ed-Dawwara: an Iron Age site northeast of Jerusalem. Tel Aviv, v. 17, n. 2, p. 163-208, 1990.

FINKELSTEIN, I. O reino esquecido: arqueologia e história de Israel Norte. Trad. Silas Klein Cardoso e Élcio V. S. Mendonça. São Paulo: Paulus, 2015.

FINKELSTEIN, I. Tell el-Fûl revisited: the Assyrian and Hellenistic Periods (with a new identification). PEQ, v. 143, n. 2, p.106-118, 2011.

FINKELSTEIN, I. The archaeology of the Israelite settlement. Jerusalem: IES, 1988.

FINKELSTEIN, I.; LEDERMAN, Z. (eds.). Highlands of many cultures: the southern Samaria survey. 2 vols. Tel Aviv: Institute of Archaeology of Tel Aviv University, 1997. (SMNIA, 14).

FINKELSTEIN, I.; MAGEN, Y. (eds.). Archaeological survey of the bill country of Benjamin. Jerusalem: IES, 1993.

FINKELSTEIN, I.; RÖMER, T. Kiriath-jeraim, Kiriath-baal/Baalah, Gibeah: a geographical-history challenge. In: KOCH, I.; RÖMER, T.; SERGI, O. (eds.). Writing, rewriting, and overwriting in the Books of Deuteronomy and the former Prophets. Essays in Honour of Cynthia Edenburg. Leuven; Paris; Bristol: Peeters, 2019, p. 211-222.

FINKELSTEIN, I.; SINGER-AVITZ, L. Reevaluating Bethel. ZDPV, v. 125, n. 1, p. 33-48, 2009.

GALLING, K. Beschriftete Bildsiegel des ersten Jahrtausends v. Chr. vornehmlich aus Syrien und Palästina. Ein Beitrag zur Geschichte der phönikischen Kunst. ZDPV, v. 64, n. 2, p. 121-202, 1941.

GONNERMANN, L. Isis gives life! Hieroglyphic inscriptions on Egyptian amulets found in Iron Age southern Levant. In: JONKER, L.; BERLEJUNG, A.; CORNELIUS, I. (eds.). Multilingualism in ancient contexts: perspectives from ancient Near Eastern and Christian contexts. Stellenbosch: SUN PReSS, 2021, p. 76-93.

HASEL, G. F. דיגָנ In: BOTTERWECK, G. J.; RINGGREN, H.; FABRY, H. J. (orgs.). Theological Dictionary of the Old Testament. Vol. 9. Trad. David E. Green. Grand Rapids, MI: Eerdmans Publishing, 1998, p. 187-202.

HOLLOWAY, S. W. Expansion of the historical context of the Hebrew Bible/Old Testament. In: SÆBØ, M. (ed.). Hebrew Bible/Old Testament, the history of Its interpretation: III/1: The Nineteenth Century. Göttingen: Vandenhoeck \& Ruprecht, 2013, p. 90-118.

JAEGER, B. Essai de classification et datation des scarabées Menkhéperrê. Prix de la confederation internationale des négociants en œuvres d'art 1979. Friburgo, Suíça; Göttingen: Éditions Universitaitres Fribourg Suisse; Vandenhoeck \& Ruprecht, 1982. (OBO.SA, 2).

KEEL, O. Corpus der stempelsiegel-amulette aus Palästina/Israel. Von den Anfängen bis zur Persezeit. 6 vols. (Eiletung, I, II, III, IV, V). Friburgo, Suíça; Göttingen: Universitätsverlag Freiburg; Vandenhoeck \& Ruprecht, 1995, 1997, 2010, 2010, 2013, 2017. (OBO SA, 10, 13, $27,31,33,35)$. 
KEEL, O. Die geschichte Jerusalems und die entstehung des Monotheismus. 2 vols. Göttingen: Vandenhoeck \& Ruprecht, 2007. (OLB, 4.1-2).

KEEL, O. Powerful symbols of victory, the parts stay the same, the actors change. JNSL, v. 25 , n. 2 , p. $205-240,1999$.

KEEL, O. Wirkmächtige siegeszeichen im Alten Testament. ikonographisch studien zu Jos 8, 18 26; Ex 17, 8-13; 2 Kön 13, 14-19 und 1 Kön 22, 11. Friburgo, Suíça; Göttingen: Universitätsverlag Freiburg; Vandenhoeck \& Ruprecht, 1974b. (OBO, 5).

KEEL, O.; SHUVAL, M.; UEHLINGER, C. Studien zu den stempelsiegeln aus Palästina/Israel: Band III, Die Frühe Eisenzeit, Ein Workshop. Friburgo, Suíça; Göttingen: Universitätsverlag Freiburg Schweiz; Vandenhoeck \& Ruprecht, 1990. (OBO, 1000).

KEEL, O.; UEHLINGER, C. Gods, Goddesses and images of God. Minneapolis: Fortress Press, 1998.

KELSO, J. L. The excavation of Bethel (1934-1960). Cambridge: American Schools of Oriental Research, 1968. (AASOR, 39).

KIPFER, S. Der bedrobte David: eine exegetische und rezeptionsgeschichtliche Studie zu 1Sam 16-1Kön 2. Berlin; Boston: Walter de Gruyter, 2015. (SBR, 3).

KIPFER, S.; HUTTON, J. M. The Book of Samuel and Ist response to monarchy: an introduction. In: KIPFER, S.; HUTTON, J. M. (eds.). The Book of Samuel and Its response to monarchy. Stuttgart: Kohlhammer, 2021, p. 11-21. (BWANT, 228).

KLEIN CARDOSO, S. Amuletos como mídia: poder estampado em ossos e o "Antigo Israel”. Caminhando, São Bernardo do Campo, v. 25, n. 1, p. 141-161, 2020a.

KLEIN CARDOSO, S. Javé, leão de Betel: imaginário cúltico e história em 2Rs 17. Reflexus, ano 12, v. 19, n. 1, p. 199-225, 2018.

KLEIN CARDOSO, S. Para desvendar o mundo bíblico. Entre linhas e pressupostos. In: CARNEIRO, M. S.; LEONEL, J. (eds.). Métodos de estudo da Bíblia. São Paulo: Recriar. No prelo.

KLEIN CARDOSO, S. Redes mágico-míticas no alvorecer de Israel: "religião" no platô de Benjamim no Ferro I-IIA. 2019. 450 f. Tese (Doutorado em Ciências da Religião) - Universidade Metodista de São Paulo, São Bernardo do Campo, 2019.

KLEIN CARDOSO, S. Templos da Casa de Saul? Dissonâncias entre registro bíblico e material. Caminhando, São Bernardo do Campo, v. 25, n. 2, p. 55-76, 2020 b.

KLEIN CARDOSO, S. The Goddesses and Gods of Saul. Pistis \& Práxis, v. 12, n. 2, p. 352-370, 2020c.

KNAUF, E. A.; GUILLAUME, P. A history of biblical Israel: the fate of the tribes and kingdoms from Merenptah to Bar Kochba. Sheffield; Bristol: Equinox, 2016. (Worlds of the Ancient Near East and Mediterranean).

$\mathrm{KOCH}, \mathrm{I}$. Late Iron Age I southwestern Canaanite multi-facet stamp-amulets: innovative imagery and interpreted Egyptian heritage. In: SHAI, I.; CHADWICK, J. R.; HITCHCOCK, L.; DAGAN, A.; McKINNY, C.; UZIEL, J. (eds.). Tell it in Gath, studies in the history and archaeology of Israel. Essays in Honor of Aren M. Maeir on the Occasion of his Sixtieth Birthday. Münster: Zaphon, 2018, p. 632-652. (ÄAT, 90).

NA'AMAN, N. In search of the ancient name of Khirbet Qeiyafa. JHebS, v. 8, artigo 21, p. 
2-8, 2008 .

LEDERMAN, Z. An Early Iron Age village at Khirbet Raddana: the excavations of Joseph A. Callaway. Ann Arbor: UMI Dissertation Services, 1999.

LEHMANN, G. Clan. In: ALLISON, D.C. et al. (eds.). Encyclopedia of the Bible and its reception. Berlin: De Gruyter, 2012, p. 381-385.

LEHMANN, G. Reconstructing the social landscape of Early Israel: rural marriage alliances in the central hill country. Tel Aviv, v. 31, n. 2, p. 141-193, 2004.

LEHMANN, G.; VARONER, O. Early Iron Age tombs in northern Israel revisited. Tel Aviv, v. 45, n. 2, p. 235-272, 2018.

LEV-YADUN, S. Flora and climate in southern Samaria: past and present. In: FINKELSTEIN, I.; LEDERMAN, Z. (eds.). Highlands of many cultures: the southern Samaria survey. 2 vols. Tel Aviv: Institute of Archaeology of Tel Aviv University, 1997, p. 85-102. (Tel Aviv University. Monograph Series, 14).

LIPSCHITS, O. The fall and rise of Jerusalem: Judah under Babylonian rule. Winona Lake, IN: Eisenbrauns, 2005.

LIVINGSTONE, D. P. Kbirbet Nisya: the search for biblical Ai, 1979-2002. Excavation of the site with Related Studies in Biblical Archaeology. Pennsylvania: Masthof Press, 2012.

MARQUET-KRAUSE, J. Les fomilles de 'Ay (Et-Tell), 1933-1935: la résurrection d'une grande cité biblique. Paris: Geuthner, 1949. (BAH, 45).

McKENZIE, S. L. Saul in the Deuteronomistic History. In: EHRLICH, C. S. (ed.). Saul in story and tradition. Tübingen: Mohr Siebeck, 2006, p. 59-70. (FAT, 47).

McCOWN, C. C. Tell en-Nasḅeh I: archaeological and historical results. Berkeley; New Haven: The Palestine Institute of Pacific School of Religion; AASOR, 1947.

MILLER II, R. D. Chieftains of the highland clans: history of Israel in twelfth and eleventh centuries B.C. Grand Rapids, MI: Eerdmans, 2005.

MÜNGER, S. Studien zur Frühen eisenzeit in Israel/Palästina. 2011. 387 f. Dissertation (Th.D. in evangelischer Theologie) — Theologischen Fakultät, Universität Bern, 2011.

ORNAN, T.; LIPSCHITS, O. The lion stamp impressions from Judah: typology, distribution, iconography, and historical implications. A preliminary report. Semitica, v. 62, p. 69-91, 2020.

ORNAN, T.; WEKSLER-BDOLAH, S.; KISILEVITZ, S.; SASS, B. "The Lord will roar from Zion" (Amos 1:2). The lion as a divine attribute on a Jerusalem seal and other Hebrew glyptic finds from the western Wall Plaza excavations. 'Atiqot, v. 72, p. 1-13, 2012. PELEG, Y.; YEZERSKI, I. A dwelling and burial cave at Kh. Abū-Musarra $\square$ in the land of Benjamin. In: HIZMI, H.; DE GROOT, A. (eds.). Burial caves and sites in Judea and Samaria: from the Bronze and Iron Ages. Jerusalem: IES, 2004, p. 107-156. (Judea \& Samaria Publications, 4).

PIETSCH, M. König / Königtum (AT). In: Das Wissenschaftliche Bibellexikon im internet, 2014. Disponível em: http://www.bibelwissenschaft.de/stichwort/23844/. Acesso em $15 / 06 / 2021$.

PRITCHARD, J. B. The Bronze Age cemetery at Gibeon. Philadelphia: University Museum; University of Pennsylvania, 1963.

PRITCHARD, J. B. The water system of Gibeon. Philadelphia: University of Pennsylvania; 
University Museum, 1961.

PRITCHARD, J. B. Winery, defenses, and soundings at Gibeon. Philadelphia: University Museum; University of Pennsylvania, 1964.

RYAN, M-. L. Avatars of story. Minneapolis; London: University of Minnesota Press, 2006. (Eletronic Mediations, 17).

SASS, B. The Pre-Exilic Hebrew seals: iconism vs. aniconism. In: SASS, B.; UEHLINGER, C. (eds.). Studies in the iconography of northwest semitic inscribed seals. Proceedings of a symposium held in Fribourg on april 17-20, 1991. Friburgo, Suíça; Göttingen: University Press Fribourg; Vandenhoeck \& Ruprecht, 1993, p. 194-256. (OBO, 125).

SCHMITT, R. Bildhafte Herrschaftsrepräsentation im eisenzeitlichen Israel. Münster: Ugarit-Verlag, 2001. (AOAT, 283).

SCHROER, Silvia. Die ikonographie Palästinas/Israels und der Alte Orient. eine Religionsgeschichte in Bildern. 4 vols. Fribourg: Schwabe; Bibel+Orient Museum, 2005 [c/ KEEL, Othmar], 2008, 2011, 2018.

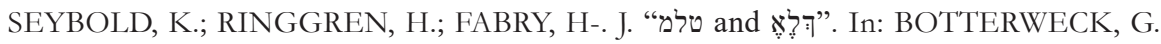
Johannes (org.). Theological Dictionary of the Old Testament. Vol. 8. Trad. Douglas W. Stott. Grand Rapids, MI: Eerdmans, 1997, p. 346-375.

TOORN, K.V. D. Family religion in Babylonia, Syria and Israel: continuity and change in the forms of religious life. Atlanta: SBL Press, 1996. (SHCANE, 7).

UEHLINGER, C. Der Amun-Tempel Ramses` III. in $p 3-K n$ 'n, seine süd-oalästinischen Tempelgüter und der Übergang von der Ägypter- zur Philisterherrschaft: ein Hinweis auf einige wenig beachtete Skarabäen. In: KEEL, O.; SHUVAL, M.; UEHLINGER, C. Studien $z u$ den stempelsiegeln aus Palästina/Israel. Band III: Die Frühe Eisenzeit, ein Workshop. Friburgo, Suíça; Göttingen: Universitätsverlag Freiburg Schweiz; Vandenhoeck \& Ruprecht, 1990, p. 3-26. (OBO, 1000).

ZORN, J. R. Jeremiah at Mizpah of Benjamin (Tell en-Nasbeh): the archaeological setting. In: LUNDBOM, J. R.; EVANS, C. R.; ANDERSON, B. A. The Book of Jeremiab: composition, reception, and interpretation. Leiden: Brill, 2018, p. 69-92. (VTSup, 178).

ZORN, J. R. Tell en-Naspeh: a re-evaluation of the architecture and stratigraphy of the Early Bronze Age, Iron Age and later periods. Vol I-IV. 1993. 1707 f. Tese (doutorado em Near Eastern Studies) - Graduate Division of the University of California at Berkeley, 1993.

ZORN, J. R. Tell en-Nasbeh and the problem of the material culture of the sixth century. In: LIPSCHITS, O.; BLENKINSOPP, J. (eds.). Judah and the judeans in the Neo-Babylonian Period. Winona Lake, IN: Eisenbrauns, 2003, p. 413-447. 